\title{
A framework for prioritizing customer requirements in product design: Incorporation of FAHP with AHP
}

\author{
M.T. Mastura ${ }^{1,2}$, S.M. Sapuan ${ }^{1,3, *}$ and M.R. Mansor ${ }^{2}$ \\ ${ }^{1}$ Faculty of Engineering, Universiti Putra Malaysia, \\ 43400 UPM Serdang, Selangor, Malaysia \\ ${ }^{2}$ Faculty of Mechanical Engineering, Universiti Teknikal Malaysia Melaka, \\ Hang Tuah Jaya, 76100 Durian Tunggal, Melaka, Malaysia \\ ${ }^{3}$ Institute of Tropical Forestry and Forest Products, Universiti Putra Malaysia, \\ 43400 UPM Serdang, Selangor, Malaysia \\ *Email: sapuan@upm.edu.my \\ Phone: +6038947 1788; Fax: +6038947 1896
}

\begin{abstract}
Prioritizing customer requirements in product design requires a tool that could help design engineers make the right decisions at the early stages of the design process. In this paper, a framework incorporating the fuzzy analytic hierarchy process (FAHP) with extent analysis with the analytic hierarchy process (AHP) has been proposed in order to overcome the problems of consistent judgement in FAHP and solve conventional AHP problems in dealing with subjective judgement, especially in prioritizing customer requirements. Based on the case study presented, by incorporating FAHP with AHP, the results are not very different from each other where the ranking of the customer requirements is similar, which implies the validity of FAHP in evaluating customer requirements. The consistency ratio obtained is as much as $8.51 \%$, which is less than $10 \%$. Thus, the consistency of the judgement can be evaluated, while the proposed framework is able to judge imprecise and vague information. Moreover, the incorporation of both methods is applicable and analysis of the consistency ratio from a fuzzy environment is possible.
\end{abstract}

Keywords: Customer requirements; Fuzzy Analytic Hierarchy Process; Analytic Hierarchy Process; design process.

\section{INTRODUCTION}

Customer requirements are important elements that have to be considered for product design development. When designing a product, input from customers is very useful in order to produce a marketable product and reach sales department targets. The views of customers can be collected from interviews, questionnaires and other survey methods [1]. When it comes to human judgement, the results are subjective and it is not easy for the decision maker to decide the preferences. In common practice, customers are given an option to rate their judgement based on a verbal or numerical scale. The verbal scale is in a range from equally preferred to extremely strongly preferred, while the numerical scale is generally a nine-point scale to show the level of preference. Furthermore, the results from customers vary and it is difficult for the design engineer to determine what is the most preferred requirement for the product. Imprecise and vague information in the prioritizing process makes it difficult to determine the final importance ratings [2]. Consistency is one of the key factors when evaluating customer requirements. Human 
judgement is influenced by surroundings and feelings, which implies that it will usually be vague [3]. Therefore, consistency has to be checked in every judgement to avoid any mistake during decision making. From the feedback of the customers, it seems that everything is important and satisfying one requirement may disfavour another requirement. Moreover, decision makers have to choose the most appropriate decision making tools to help them to evaluate the judgement. In order to select the most suitable tools, the decision maker has to identify the tool that he/she is comfortable with in order to avoid any misleading result that might cause a false decision. The most appropriate tools are there for them to choose based on their knowledge and understanding to make the decision making process less complicated and quicker.

There is a tool in the multi-criteria decision making (MCDM) method that can derive the ranking of requirements and set the preferences numerically. Thomas L. Saaty [4] developed AHP to help decision makers make consistent judgements. The analytic hierarchy process is a mathematical tool that can derive a priority vector from a consistent matrix which contains pairwise comparison of the requirements [5]. This priority vector is known as the principal eigenvector and indicates the order of preference and reflects this in ratios of numerical value [6]. However, AHP seems to be insufficient and too imprecise to derive the importance rates of customer requirements due to the uncertainty and vagueness that is attributed to the judgement of those customer requirements [7]. There is another tool that extends the analysis of AHP in a fuzzy environment, FAHP with extent analysis, which has shown its ability to overcome vague and imprecise judgements but still lacks consistency of evaluation [8]. Hence, both these methods can be applied in prioritizing customer requirements and the idea of incorporating both methods may enhance the decision making outcome.

In this study, a proposed framework will be introduced in order to help the design engineer to determine the importance rating of customer requirements using an integrated method of MCDM in fuzzy and non-fuzzy environments. Incorporation of AHP into FAHP with the extent analysis framework will help the design engineer to decide which requirements from customers are consistently most strongly preferred over others after considering the benefits from the fuzzy and non-fuzzy environments.

\section{RELATED WORKS}

\section{Analytic Hierarchy Process}

The analytic hierarchy process (AHP) is a tool that has been used by many researchers in many applications [9]. For example, AHP has been used to determine the best concept design of a product and also to determine a suitable material for the product design. Table 1 shows examples of the application of AHP reported by researchers in solving other design problems. Furthermore, an integrated method in product design development has been used widely in various stages [16]. A method integrating AHP with other tools for product design has been introduced by many researchers, such as Mansor et al. [17], who integrated AHP with a Technique for Order Preference by Similarity (TOPSIS) in order to select a thermoplastic matrix for the formulation of hybrid natural fibre composites at the material selection stage. Other than that, Hanumaiah et al. [18] introduced the integration of AHP with quality function deployment (QFD) in order to select the most appropriate tooling process for process selection in product design. Minyt [19] also proposed a framework of intelligent quality function deployment (IQFD), which is a compromise AHP in the framework with application in discrete parts in the assembly 
environment. Hence, the simplicity of the algorithm of the AHP has allowed this tool to be integrated with other methods in order to enhance the quality of the decision since the consistency of the decision will be evaluated from this method. In prioritizing customer requirements, it offers greater benefits and helps the design engineer to identify the most and least important requirements for the product design based on customer feedback.

Table 1. Application of AHP related to design problems.

\begin{tabular}{clc}
\hline No & \multicolumn{1}{c}{ Design Problem } & Reference \\
\hline 1 & $\begin{array}{l}\text { Determination of the most suitable design concept for wheelchair } \\
\text { design }\end{array}$ & {$[10]$} \\
2 & $\begin{array}{l}\text { Determination of the most appropriate decisions on the design } \\
\text { concept and material concurrently at the early stage of the product } \\
\text { development process or conceptual design stage }\end{array}$ & {$[11]$} \\
3 & $\begin{array}{l}\text { Determination of the most suitable material for an automotive } \\
\text { dashboard panel }\end{array}$ & {$[12]$} \\
4 & $\begin{array}{l}\text { Determination of the degree of importance of criteria to overcome the } \\
\text { shortcomings in material selection during the design process }\end{array}$ & {$[13]$} \\
5 & $\begin{array}{l}\text { Selection of the most suitable natural fibre to be hybridized with glass } \\
\text { fibre reinforced polymer composites for the design of a passenger } \\
\text { vehicle centre lever parking brake component } \\
\text { Selection of the best concept design of an automotive component } \\
\text { based on the product design specifications }\end{array}$ & {$[14]$} \\
\hline
\end{tabular}

\section{Fuzzy AHP with Extent Analysis}

Chang [8] in his research has introduced FAHP with extent analysis to obtain a crisp priority vector from a triangular fuzzy comparison matrix. This method converts the linguistic assessment to a triangular fuzzy number. The "extent analysis" here is referred to as a consideration of the extent to which an object satisfies the goal [20]. Although FAHP has been criticized by the architect of conventional AHP itself, Saaty in his papers [21]-[23], numerous researchers are still using fuzzy judgement from FAHP to determine the importance weights in many product design applications. These include a study done by Kwong and Bai [20] that utilized FAHP to determine the importance weights for customer requirements. Chan et al. [24] also reported that FAHP could be used to determine the relative importance of product life cycle phases and the main criteria within each phase through pairwise comparison. This was followed by Wang [25], who utilized FAHP to determine the relative importance evaluation criteria in assessing environmental performance with respect to different product designs. FAHP seems to be a suitable approach to analyse human judgement in uncertain environments [26]. On the other hand, Roy [27] in his study reported that AHP does not perfectly reflect the decision maker's thought and may fail to give accurate preferences due to imprecise information.

Generally, like AHP, FAHP with extent analysis has been integrated with other tools such as QFD, TOPSIS, VIKOR (Vise Kriterijumska Optimizacija I Kompromisno Resenje), the artificial neural network approach and Fuzzy TOPSIS in many applications including logistics, manufacturing and product design [28]-[31]. Moreover, a methodology has been developed including house of quality, FAHP and rough-grey analysis to enable designers to make better decisions before finalizing their choices [32]. 
The triangular fuzzy numbers that have been used in applications of FAHP would give a better result in making a decision. In a study by Ishizaka [33], in supplier selection, it is difficult to evaluate the judgement because of the complexity, vagueness and uncertainty of the problem. In his study, the example of evaluation between scale 4 and 6 would lead to the incorporation of fuzzy numbers that will give greater precision. Based on the disadvantage of AHP that it fails to give accurate preferences with imprecise information, and its advantage in terms of judgement consistency, as mentioned earlier, the incorporation of AHP with FAHP with extent analysis is more preferable and would combine the benefits from both of these methods.

\section{PROPOSED FRAMEWORK}

The methodology of FAHP with extent analysis and the AHP approach in prioritizing customer requirements is proposed in this study as shown in Figure 1. FAHP with extent analysis and conventional AHP methods are applied in parallel for the proposed framework. Initially, the hierarchy of attributes was constructed. Here, the goal of the decision making is set at level 1 at the top of the hierarchy, and decomposition of the main goal into sub-goals or criteria is set at level 2 of the hierarchy. At level 3, there are alternatives that need to be decided according to the goal. In this case, level 1 is set as a goal to prioritize the customer requirements for the product design. Level 2 contains the criteria that are required for product design, such as cost, quality and environment. Next, in the list of level 3 customer requirements are the alternatives that need to be prioritized in order to achieve the goal at level 1. An illustration of the hierarchy is shown in Figure 2.

Later, each of the elements was compared with another on a pairwise basis using the algorithm of FAHP with extent analysis and AHP. A nine-point scale is used as this is commonly used to show the judgement or preference between options, as equally, moderately, strongly, very strongly, or extremely preferred. For FAHP, the triangular fuzzy number technique is used to represent pairwise comparisons and the same scale of crisp numbers was applied for the pairwise comparison matrix in AHP.

\section{Methodology of Fuzzy AHP with Extent Analysis}

A triangular fuzzy number can be denoted as $\mathrm{M}=\tilde{\mathrm{a}}_{i j}=\left(l_{i j}, m_{i j}, u_{i j}\right)$, where $l \leq m \leq u, l$ and $u$ stand for the lower and upper value of the support $\mathrm{M}$, respectively and $m$ is the mid value of M. Triangular fuzzy numbers are used to represent the assessment from equal to extremely preferred for the scale $\mathrm{M}_{1}, \mathrm{M}_{3}, \mathrm{M}_{5}, \mathrm{M}_{7}$ and $\mathrm{M}_{9}$, while $\mathrm{M}_{2}, \mathrm{M}_{4}, \mathrm{M}_{6}$ and $\mathrm{M}_{8}$ are used to represent the moderate values. Table 2 shows the triangular fuzzy numbers conversion scale of the linguistic values and the crisp values in the weighting set used by decision makers [20]. 


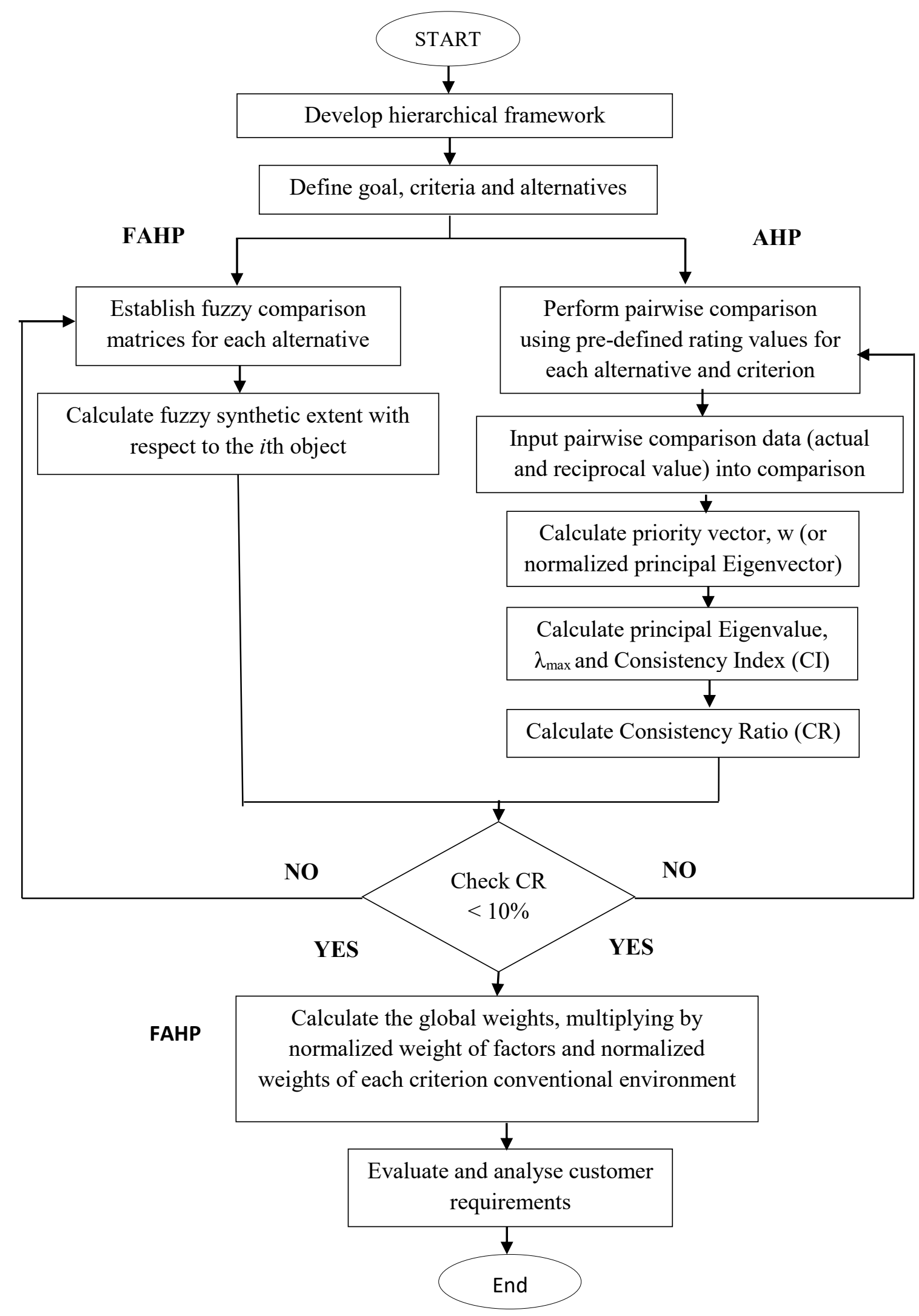

Figure 1. Framework of methodology of FAHP with extent analysis and AHP in prioritizing customer reauirements.

\section{Prioritizing customer requirements}

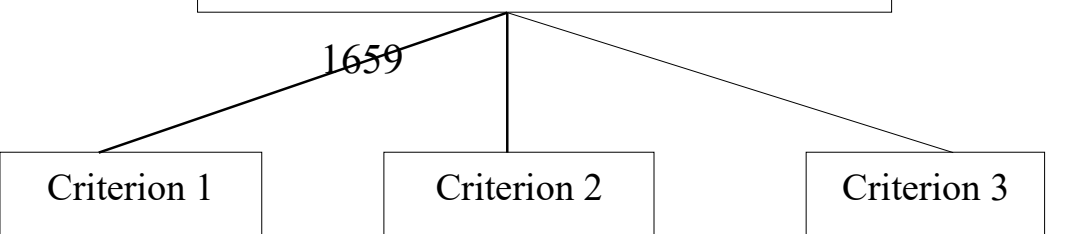


Level 1: Goal

Level 2: Criteria

Level 3: Alternatives

Figure 2. The hierarchy framework.

Table 2. Triangular fuzzy numbers and crisp numbers in the weighting set used by decision makers.

\begin{tabular}{ccc}
\hline \multicolumn{2}{c}{ Intensity of preference } & Verbal Definition \\
\cline { 1 - 2 } Number & $\begin{array}{c}\text { Triangular } \\
\text { Fuzzy } \\
\text { Number }\end{array}$ & \\
\hline 1 & $1,1,2$ & Equally preferred \\
2 & $1,2,3$ & Equally to moderately preferred \\
3 & $2,3,4$ & Moderately preferred \\
4 & $3,4,5$ & Moderately to strongly preferred \\
5 & $4,5,6$ & Strongly preferred \\
6 & $5,6,7$ & Moderately to very strongly \\
& & preferred \\
7 & $6,7,8$ & Very strongly preferred \\
8 & $7,8,9$ & Moderately to extremely strongly \\
& & preferred \\
9 & $8,9,9$ & Extremely strongly preferred \\
\hline
\end{tabular}

Next, a triangular fuzzy comparison matrix is expressed as in Eq. (1):

$$
\tilde{A}=\left(\tilde{\mathrm{a}}_{i j}\right)_{n \times n}=\left[\begin{array}{cccc}
(1,1,1) & \left(l_{12}, m_{12}, u_{12}\right) & \ldots & \left(l_{1 n}, m_{1 n}, u_{1 n}\right) \\
\vdots & (1,1,1) & \ldots & \vdots \\
\left(l_{n 1}, m_{n 1}, u_{n 1}\right) & \left(l_{n 2}, m_{n 2}, u_{n 2}\right) & \ldots & (1,1,1)
\end{array}\right]
$$

where $\tilde{\mathrm{a}}_{\mathrm{ij}}=\left(l_{i j}, m_{i j}, u_{i j}\right)$ and $\tilde{\mathrm{a}}_{\mathrm{ij}}{ }^{-1}=\left(1 / u_{i j}, 1 / m_{i j}, 1 / l_{i j}\right)$ for $i, j=1, \ldots, n$ and $i \neq j$.

An extent analysis method was used to calculate the priority vector of the above triangular fuzzy comparison matrix from formulas suggested by Chang [8] and modified by several researchers [27], [34], [35] as follows: 
Step 1: Each row of the fuzzy comparison matrix $\tilde{A}$ is summed up by fuzzy arithmetic operations as in Eq. (2):

$$
\mathrm{RS}_{\mathrm{i}}=\sum_{j=1}^{n} \tilde{\mathrm{a}}_{i j}=\left(\sum_{j=1}^{n} l_{i j}, \sum_{j=1}^{n} m_{i j}, \sum_{j=1}^{n} u_{i j}\right), i=1, \ldots, n
$$

Step 2: According to Wang [35], the normalization formula suggested by Chang [8] led to a wrong decision and some information from the comparison matrices would be wasted. Therefore, he suggested a normalization formula for a set of triangular fuzzy weights as in Eq. (3):

$$
\widetilde{S_{l}}=\frac{R S_{i}}{\sum_{j=1}^{n} R S_{j}}=\left(\begin{array}{c}
\frac{\sum_{j=1}^{n} l_{i j}}{\sum_{j=1}^{n} l_{i j}+\sum_{k=1, k \neq i}^{n} \sum_{j=1}^{n} u_{k j}}, \frac{\sum_{j=1}^{n} m_{i j}}{\sum_{k=1}^{n} \sum_{j=1}^{n} m_{k j}}, \\
\frac{\sum_{j=1}^{n} u_{i j}}{\sum_{j=1}^{n} u_{i j}+\sum_{k=1, k \neq i}^{n} \sum_{j=1}^{n} l_{k j}}
\end{array}\right), i=1, \ldots, \mathrm{n}
$$

Step 3: Wang [35] and Zhu [36] mentioned that Chang's suggestion on the definition of the priority vector does not reflect the true priorities and cannot be used to find the relative priority values. Therefore, Roy et al. [27] considered the method suggested by Liou and Wang [37] for finding the priorities of synthetic extent. Roy et al. [27] used the total integral value method developed by Liou and Wang [37] to deal with the zero-weight problem found in Chang's method. The formula to find the total integral value is shown in Eq. (4):

$$
J_{T}^{\alpha}\left(S E_{j}\right)=\frac{1}{2} \alpha\left(b_{j}+c_{j}\right)+\frac{1}{2}(1-\alpha)\left(a_{j}+b_{j}\right)=\frac{1}{2}\left[\alpha c_{j}+b_{j}+(1-\alpha) a_{j}\right]
$$

where $\alpha$ represents the degree of optimism of the decision maker and its value can range from 0 to 1 . When $\alpha=0$, it represents the pessimistic decision maker's point of view and $\alpha=1$ represents the optimistic decision maker's point of view. Thus, in this study $\alpha=0.5$ was used to represent moderation.

Step 4: Next, the normalized priority vector $W=\left(w_{1}, w_{2}, \ldots, w_{n}\right)^{\mathrm{T}}$, a non-fuzzy number, is calculated by Eq. (5):

$$
w_{j}=\frac{J_{T}^{\alpha}\left(S E_{j}\right)}{\sum_{j=1}^{n} J_{T}^{\alpha}\left(S E_{j}\right)}
$$

\section{Methodology of Analytic Hierarchy Process}

In AHP, the common hierarchy is used and the nine-point scale with conversion value from triangular fuzzy numbers to crisp numbers is used to construct pairwise comparison matrixes. In order to obtain priority vectors, the principal eigenvector of comparison matrix, $A$ as in Eq. (6) will be calculated.

$$
A=\left(\mathrm{a}_{i j}\right)_{n \times n}=\left[\begin{array}{cccc}
\mathrm{a}_{11} & \mathrm{a}_{12} & \cdots & \mathrm{a}_{1 n} \\
\vdots & 1 & \ldots & \vdots \\
\left(\mathrm{a}_{n 1}\right. & \mathrm{a}_{n 2} & \ldots & 1
\end{array}\right]
$$

where $\mathrm{a}_{\mathrm{ij}}=k$ automatically implies that $\mathrm{a}_{\mathrm{ji}}=1 / k$ and $i, j=1, \ldots, n$ and $i \neq j$. 
As in Saaty's [5] approach, the priority vector is the vector $\boldsymbol{w}$ that are normalized components of the eigenvector corresponding to the largest eigenvalue, $\lambda_{\max }$ as in Eq. (7):

$$
A \boldsymbol{w}=\lambda_{\max } \boldsymbol{w}
$$

A priority vector, $\boldsymbol{w}$, must satisfy the above relationship with a positive eigenvalue to remain invariant under the hierarchic composition principle so that it does not keep getting new priority vectors from the matrix if the judgement is changing [38]. This would show the consistency of the judgement. The eigenvalue of the comparison matrix, $A$, is used to indicate the degree of inconsistency of matrix $A$. The consistency index $(\mathrm{CI})$ and consistency ratio (CR) for a comparison matrix can be computed from Eq. (8) and Eq. (9) respectively:

$$
\begin{aligned}
\mathrm{CI} & =\frac{\lambda_{\max }-n}{n-1} \\
\mathrm{CR} & =\left(\frac{\mathrm{CI}}{R I(n)}\right) 100 \%
\end{aligned}
$$

where, $\lambda_{\max }$ is the largest eigenvalue of the comparison matrix, $n$ is the dimension of the matrix and $R I(n)$ is a random index that depends on $n$ as shown in Table 3 . If the calculated consistency ratio is less than $10 \%$, the pairwise judgement can be thought of as acceptable.

Table 3. Random index $(R I(n))$ of random matrix [39].

\begin{tabular}{rrrrrrrrrrrrrr}
\hline $\mathrm{n}$ & 3 & 4 & 5 & 6 & 7 & 8 & 9 & 10 & 11 & 12 & 13 & 14 & 15 \\
\hline $\mathrm{RI}(\mathrm{n})$ & 0.58 & 0.9 & 1.12 & 1.24 & 1.32 & 1.41 & 1.45 & 1.49 & 1.51 & 1.48 & 1.56 & 1.57 & 1.59 \\
& & & & & & & & & & & & & \\
\hline
\end{tabular}

\section{CASE STUDY}

In this study, the design requirements for an automotive anti-roll bar (ARB) are taken as a case study. The case study is carried out to obtain the validity of the proposed framework and improve the proposal. Here, the requirements from the customers were collected and the next activities will be explained in the following section.

\section{Development of Hierarchical Framework}

A list of customer requirements was collected from related studies for the design of an ARB [40]-[47] as summarized in Figure 3. At level 1, the main goal is to prioritize customer requirements that are divided into sub-goals in terms of the cost, quality and environmental aspect in level 2. A list of the customer requirements can be found at level 3. All the requirements that are obtained have considered the operation of the ARB and the pre- and post-process of its development. Cost is an expected requirement since the automotive ARB is applicable for all types of vehicle. The operation of the ARB includes bending and torsion load, and it is expected that the design of the ARB must be durable, reliable and stiff enough to withstand the loading during operation. In terms of the environment, the process of the automotive ARB must be environmentally safe and free from any hazardous substance. Thus, design engineers need to identify the most and least important customer requirements to consider for the design of the automotive ARB. 
Level 1: Goal

Level 2: Criteria

Level 3: Alternatives

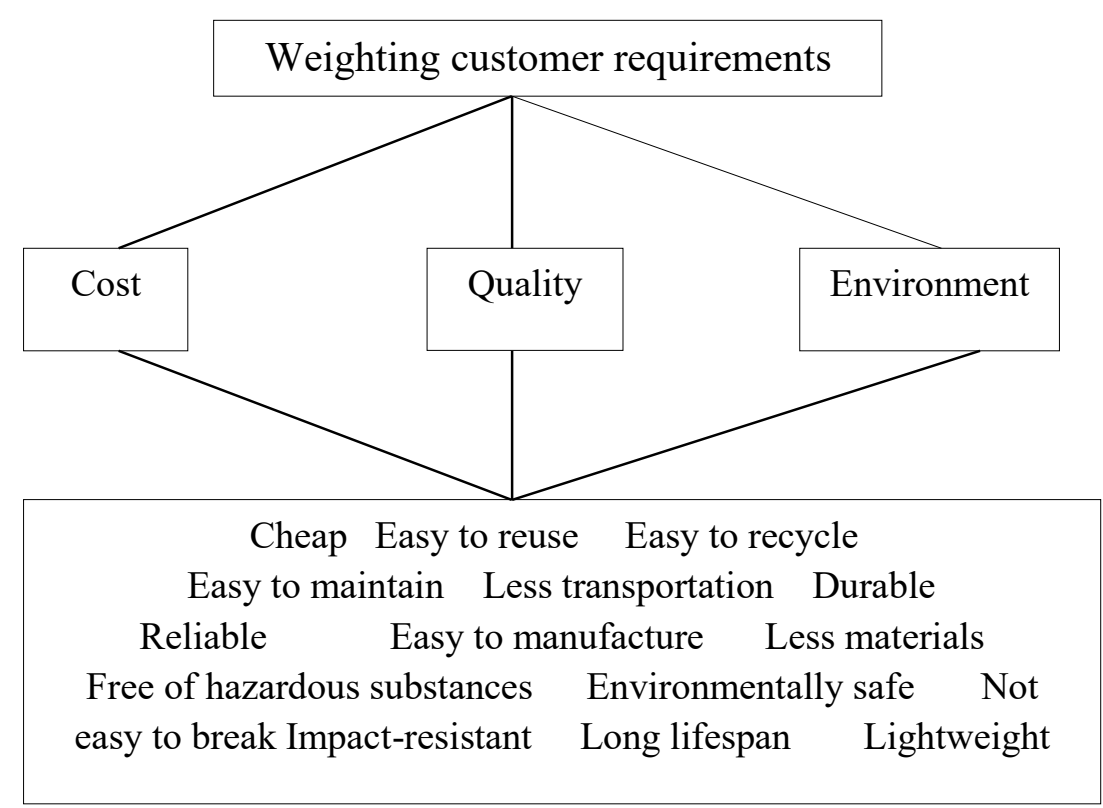

Figure 3. The hierarchy framework in prioritizing customer requirements.

Table 4. Pairwise comparison matrix of alternatives with respect to the environment criteria using AHP.

\begin{tabular}{|c|c|c|c|c|c|c|c|c|c|c|c|c|c|c|c|}
\hline & CH & ERU & ERC & LT & EF & D & LW & EM & R & LL & EI & NB & FH & LM & ES \\
\hline CH & 1.0000 & 0.1111 & 0.1111 & 0.1111 & 0.5000 & 0.1429 & 0.5000 & 0.5000 & 0.3333 & 0.3333 & 0.5000 & 0.3333 & 0.1111 & 0.3333 & 0.1111 \\
\hline ERU & 9.0000 & 1.0000 & 3.0000 & 4.0000 & 7.0000 & 4.0000 & 9.0000 & 9.0000 & 4.0000 & 6.0000 & 5.0000 & 5.0000 & 0.2500 & 6.0000 & 2.0000 \\
\hline ERC & 9.0000 & 0.3333 & 1.0000 & 3.0000 & 7.0000 & 3.0000 & 9.0000 & 9.0000 & 3.0000 & 4.0000 & 5.0000 & 5.0000 & 0.2500 & 5.0000 & 2.0000 \\
\hline LT & 9.0000 & 0.2500 & 0.3333 & 1.0000 & 6.0000 & 3.0000 & 9.0000 & 9.0000 & 4.0000 & 3.0000 & 5.0000 & 4.0000 & 0.3333 & 5.0000 & 2.0000 \\
\hline EF & 2.0000 & 0.1429 & 0.1429 & 0.1667 & 1.0000 & 0.2000 & 2.0000 & 2.0000 & 0.3333 & 0.5000 & 0.5000 & 0.3333 & 0.1429 & 0.2500 & 0.1429 \\
\hline D & 7.0000 & 0.2500 & 0.3333 & 0.3333 & 5.0000 & 1.0000 & 5.0000 & 7.0000 & 2.0000 & 3.0000 & 4.0000 & 3.0000 & 0.2000 & 3.0000 & 0.3333 \\
\hline LW & 2.0000 & 0.1111 & 0.1111 & 0.1111 & 0.5000 & 0.2000 & 1.0000 & 2.0000 & 0.3333 & 0.3333 & 0.3333 & 0.3333 & 0.1111 & 0.2500 & 0.1111 \\
\hline EM & 2.0000 & 0.1111 & 0.1111 & 0.1111 & 0.5000 & 0.1429 & 0.5000 & 1.0000 & 0.2500 & 0.3333 & 0.5000 & 0.2500 & 0.1111 & 0.2000 & 0.1111 \\
\hline R & 3.0000 & 0.2500 & 0.3333 & 0.2500 & 3.0000 & 0.5000 & 3.0000 & 4.0000 & 1.0000 & 2.0000 & 2.0000 & 2.0000 & 0.2000 & 0.5000 & 0.3333 \\
\hline LL & 3.0000 & 0.1667 & 0.2500 & 0.3333 & 2.0000 & 0.3333 & 3.0000 & 3.0000 & 0.5000 & 1.0000 & 2.0000 & 0.5000 & 0.1429 & 0.5000 & 0.3333 \\
\hline EI & 2.0000 & 0.2000 & 0.2000 & 0.2000 & 2.0000 & 0.2500 & 3.0000 & 2.0000 & 0.5000 & 0.5000 & 1.0000 & 0.5000 & 0.2000 & 0.3333 & 0.2000 \\
\hline NB & 3.0000 & 0.2000 & 0.2000 & 0.2500 & 3.0000 & 0.3333 & 3.0000 & 4.0000 & 0.5000 & 2.0000 & 2.0000 & 1.0000 & 0.1429 & 0.3333 & 0.2500 \\
\hline FH & 9.0000 & 4.0000 & 4.0000 & 3.0000 & 7.0000 & 5.0000 & 9.0000 & 9.0000 & 5.0000 & 7.0000 & 5.0000 & 7.0000 & 1.0000 & 7.0000 & 2.0000 \\
\hline LM & 3.0000 & 0.1667 & 0.2000 & 0.2000 & 4.0000 & 0.3333 & 4.0000 & 5.0000 & 2.0000 & 2.0000 & 3.0000 & 3.0000 & 0.1429 & 1.0000 & 0.2000 \\
\hline ES & 9.0000 & 0.5000 & 0.5000 & 0.5000 & 7.0000 & 3.0000 & 9.0000 & 9.0000 & 3.0000 & 3.0000 & 5.0000 & 4.0000 & 0.5000 & 5.0000 & 1.0000 \\
\hline
\end{tabular}

\section{Prioritizing Customer Requirements}

In this section, only the pairwise comparison matrix for the criteria with respect to the environment is shown in Tables 4 and $5(\mathrm{a}-\mathrm{b})$. All the attributes in level 3 of the hierarchy are compared on a pairwise basis with respect to the environment. The more important an attribute is when compared with another attribute, the higher on the scale it is rated. As mentioned before, a nine-point scale is used in the evaluation in order to rate the importance of the attributes compared with other attributes with respect to the environment, ranging from equally important to extremely strongly important. 
Journal of Mechanical Engineering and Sciences (JMES)

ISSN (Print): 2289-4659; e-ISSN: 2231-8380; Volume 9, pp. 1655-1670, December 2015

(C) Universiti Malaysia Pahang, Malaysia

DOI: http://dx.doi.org/10.15282/jmes.9.2015.12.0160

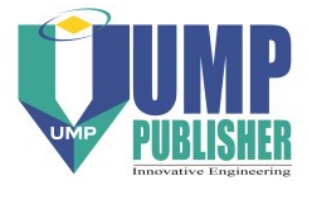

Table 5(a). Fuzzy pairwise comparison matrix with respect to environment using FAHP.

\begin{tabular}{|c|c|c|c|c|c|c|c|c|c|c|c|c|c|c|c|c|c|c|c|c|c|}
\hline & \multicolumn{3}{|c|}{$\mathrm{CH}$} & \multicolumn{3}{|c|}{ ERU } & \multicolumn{3}{|c|}{ ERC } & \multicolumn{3}{|c|}{ LT } & \multicolumn{3}{|c|}{$\mathrm{EF}$} & \multicolumn{3}{|c|}{$\mathrm{D}$} & \multicolumn{3}{|c|}{ LW } \\
\hline $\mathrm{CH}$ & 1 & 1 & 1 & $1 / 9$ & $1 / 9$ & $1 / 8$ & $1 / 9$ & $1 / 9$ & $1 / 8$ & $1 / 9$ & $1 / 9$ & $1 / 8$ & $1 / 3$ & $1 / 2$ & 1 & $1 / 8$ & $1 / 7$ & $1 / 6$ & $1 / 3$ & $1 / 2$ & 1 \\
\hline ERU & 8 & 9 & 9 & 1 & 1 & 1 & 2 & 3 & 4 & 3 & 4 & 5 & 6 & 7 & 8 & 3 & 4 & 5 & 8 & 9 & 9 \\
\hline ERC & 8 & 9 & 9 & $1 / 4$ & $1 / 3$ & $1 / 2$ & 1 & 1 & 1 & 2 & 3 & 4 & 6 & 7 & 8 & 2 & 3 & 4 & 8 & 9 & 9 \\
\hline LT & 8 & 9 & 9 & $1 / 5$ & $1 / 4$ & $1 / 3$ & $1 / 4$ & $1 / 3$ & $1 / 2$ & 1 & 1 & 1 & 5 & 6 & 7 & 2 & 3 & 4 & 8 & 9 & 9 \\
\hline EF & 1 & 2 & 3 & $1 / 8$ & $1 / 7$ & $1 / 6$ & $1 / 8$ & $1 / 7$ & $1 / 6$ & $1 / 7$ & $1 / 6$ & $1 / 5$ & 1 & 1 & 1 & $1 / 6$ & $1 / 5$ & $1 / 4$ & 1 & 2 & 3 \\
\hline D & 6 & 7 & 8 & $1 / 5$ & $1 / 4$ & $1 / 3$ & $1 / 4$ & $1 / 3$ & $1 / 2$ & $1 / 4$ & $1 / 3$ & $1 / 2$ & 4 & 5 & 6 & 1 & 1 & 1 & 4 & 5 & 6 \\
\hline LW & 1 & 2 & 3 & $1 / 9$ & $1 / 9$ & $1 / 8$ & $1 / 9$ & $1 / 9$ & $1 / 8$ & $1 / 9$ & $1 / 9$ & $1 / 8$ & $1 / 3$ & $1 / 2$ & 1 & $1 / 6$ & $1 / 5$ & $1 / 4$ & 1 & 1 & 1 \\
\hline EM & 1 & 2 & 3 & $1 / 9$ & $1 / 9$ & $1 / 8$ & $1 / 9$ & $1 / 9$ & $1 / 8$ & $1 / 9$ & $1 / 9$ & $1 / 8$ & $1 / 3$ & $1 / 2$ & 1 & $1 / 8$ & $1 / 7$ & $1 / 6$ & $1 / 3$ & $1 / 2$ & 1 \\
\hline$R$ & 2 & 3 & 4 & $1 / 5$ & $1 / 4$ & $1 / 3$ & $1 / 4$ & $1 / 3$ & $1 / 2$ & $1 / 5$ & $1 / 4$ & $1 / 3$ & 2 & 3 & 4 & $1 / 3$ & $1 / 2$ & 1 & 2 & 3 & 4 \\
\hline $\mathrm{LL}$ & 2 & 3 & 4 & $1 / 7$ & $1 / 6$ & $1 / 5$ & $1 / 5$ & $1 / 4$ & $1 / 3$ & $1 / 4$ & $1 / 3$ & $1 / 2$ & 1 & 2 & 3 & $1 / 4$ & $1 / 3$ & $1 / 2$ & 2 & 3 & 4 \\
\hline El & 1 & 2 & 3 & $1 / 6$ & $1 / 5$ & $1 / 4$ & $1 / 6$ & $1 / 5$ & $1 / 4$ & $1 / 6$ & $1 / 5$ & $1 / 4$ & 1 & 2 & 3 & $1 / 5$ & $1 / 4$ & $1 / 3$ & 2 & 3 & 4 \\
\hline NB & 2 & 3 & 4 & $1 / 6$ & $1 / 5$ & $1 / 4$ & $1 / 6$ & $1 / 5$ & $1 / 4$ & $1 / 5$ & $1 / 4$ & $1 / 3$ & 2 & 3 & 4 & $1 / 4$ & $1 / 3$ & $1 / 2$ & 2 & 3 & 4 \\
\hline $\mathrm{FH}$ & 8 & 9 & 9 & 3 & 4 & 5 & 3 & 4 & 5 & 2 & 3 & 4 & 6 & 7 & 8 & 4 & 5 & 6 & 8 & 9 & 9 \\
\hline LM & 2 & 3 & 4 & $1 / 7$ & $1 / 6$ & $1 / 5$ & $1 / 6$ & $1 / 5$ & $1 / 4$ & $1 / 6$ & $1 / 5$ & $1 / 4$ & 3 & 4 & 5 & $1 / 4$ & $1 / 3$ & $1 / 2$ & 3 & 4 & 5 \\
\hline ES & 8 & 9 & 9 & $1 / 3$ & $1 / 2$ & 1 & $1 / 3$ & $1 / 2$ & 1 & $1 / 3$ & $1 / 2$ & 1 & 6 & 7 & 8 & 2 & 3 & 4 & 8 & 9 & 9 \\
\hline
\end{tabular}

Table 5(b). Fuzzy pairwise comparison matrix with respect to environment using FAHP (continued). 


\begin{tabular}{|c|c|c|c|c|c|c|c|c|c|c|c|c|c|c|c|c|c|c|c|c|c|c|c|}
\hline \multicolumn{3}{|c|}{ EM } & \multicolumn{3}{|c|}{ R } & \multicolumn{3}{|c|}{ LL } & \multicolumn{3}{|c|}{ El } & \multicolumn{3}{|c|}{ NB } & \multicolumn{3}{|c|}{$\mathrm{FH}$} & \multicolumn{3}{|c|}{ LM } & \multicolumn{3}{|c|}{ ES } \\
\hline $1 / 3$ & $1 / 2$ & 1 & $1 / 4$ & $1 / 3$ & $1 / 2$ & $1 / 4$ & $1 / 3$ & $1 / 2$ & $1 / 3$ & $1 / 2$ & 1 & $1 / 4$ & $1 / 3$ & $1 / 2$ & $1 / 9$ & $1 / 9$ & $1 / 8$ & $1 / 4$ & $1 / 3$ & $1 / 2$ & $1 / 9$ & $1 / 9$ & $1 / 8$ \\
\hline 8 & 9 & 9 & 3 & 4 & 5 & 5 & 6 & 7 & 4 & 5 & 6 & 4 & 5 & 6 & $1 / 5$ & $1 / 4$ & $1 / 3$ & 5 & 6 & 7 & 1 & 2 & 3 \\
\hline 8 & 9 & 9 & 2 & 3 & 4 & 3 & 4 & 5 & 4 & 5 & 6 & 4 & 5 & 6 & $1 / 5$ & $1 / 4$ & $1 / 3$ & 4 & 5 & 6 & 1 & 2 & 3 \\
\hline 8 & 9 & 9 & 3 & 4 & 5 & 2 & 3 & 4 & 4 & 5 & 6 & 3 & 4 & 5 & $1 / 4$ & $1 / 3$ & $1 / 2$ & 4 & 5 & 6 & 1 & 2 & 3 \\
\hline 1 & 2 & 3 & $1 / 4$ & $1 / 3$ & $1 / 2$ & $1 / 3$ & $1 / 2$ & 1 & $1 / 3$ & $1 / 2$ & 1 & $1 / 4$ & $1 / 3$ & $1 / 2$ & $1 / 8$ & $1 / 7$ & $1 / 6$ & $1 / 5$ & $1 / 4$ & $1 / 3$ & $1 / 8$ & $1 / 7$ & $1 / 6$ \\
\hline 6 & 7 & 8 & 1 & 2 & 3 & 2 & 3 & 4 & 3 & 4 & 5 & 2 & 3 & 4 & $1 / 6$ & $1 / 5$ & $1 / 4$ & 2 & 3 & 4 & $1 / 4$ & $1 / 3$ & $1 / 2$ \\
\hline 1 & 2 & 3 & $1 / 4$ & $1 / 3$ & $1 / 2$ & $1 / 4$ & $1 / 3$ & $1 / 2$ & $1 / 4$ & $1 / 3$ & $1 / 2$ & $1 / 4$ & $1 / 3$ & $1 / 2$ & $1 / 9$ & $1 / 9$ & $1 / 8$ & $1 / 5$ & $1 / 4$ & $1 / 3$ & $1 / 9$ & $1 / 9$ & $1 / 8$ \\
\hline 1 & 1 & 1 & $1 / 5$ & $1 / 4$ & $1 / 3$ & $1 / 4$ & $1 / 3$ & $1 / 2$ & $1 / 3$ & $1 / 2$ & 1 & $1 / 5$ & $1 / 4$ & $1 / 3$ & $1 / 9$ & $1 / 9$ & $1 / 8$ & $1 / 6$ & $1 / 5$ & $1 / 4$ & $1 / 9$ & $1 / 9$ & $1 / 8$ \\
\hline 3 & 4 & 5 & 1 & 1 & 1 & 1 & 2 & 3 & 1 & 2 & 3 & 1 & 2 & 3 & $1 / 6$ & $1 / 5$ & $1 / 4$ & $1 / 3$ & $1 / 2$ & 1 & $1 / 4$ & $1 / 3$ & $1 / 2$ \\
\hline 2 & 3 & 4 & $1 / 3$ & $1 / 2$ & 1 & 1 & 1 & 1 & 1 & 2 & 3 & $1 / 3$ & $1 / 2$ & 1 & $1 / 8$ & $1 / 7$ & $1 / 6$ & $1 / 3$ & $1 / 2$ & 1 & $1 / 4$ & $1 / 3$ & $1 / 2$ \\
\hline 1 & 2 & 3 & $1 / 3$ & $1 / 2$ & 1 & $1 / 3$ & $1 / 2$ & 1 & 1 & 1 & 1 & $1 / 3$ & $1 / 2$ & 1 & $1 / 6$ & $1 / 5$ & $1 / 4$ & $1 / 4$ & $1 / 3$ & $1 / 2$ & $1 / 6$ & $1 / 5$ & $1 / 4$ \\
\hline 3 & 4 & 5 & $1 / 3$ & $1 / 2$ & 1 & 1 & 2 & 3 & 1 & 2 & 3 & 1 & 1 & 1 & $1 / 8$ & $1 / 7$ & $1 / 6$ & $1 / 4$ & $1 / 3$ & $1 / 2$ & $1 / 5$ & $1 / 4$ & $1 / 3$ \\
\hline 8 & 9 & 9 & 4 & 5 & 6 & 6 & 7 & 8 & 4 & 5 & 6 & 6 & 7 & 8 & 1 & 1 & 1 & 6 & 7 & 8 & 1 & 2 & 3 \\
\hline 4 & 5 & 6 & 1 & 2 & 3 & 1 & 2 & 3 & 2 & 3 & 4 & 2 & 3 & 4 & $1 / 8$ & $1 / 7$ & $1 / 6$ & 1 & 1 & 1 & $1 / 6$ & $1 / 5$ & $1 / 4$ \\
\hline 8 & 9 & 9 & 2 & 3 & 4 & 2 & 3 & 4 & 4 & 5 & 6 & 3 & 4 & 5 & $1 / 3$ & $1 / 2$ & 1 & 4 & 5 & 6 & 1 & 1 & 1 \\
\hline
\end{tabular}


From all the comparison matrices, the criteria and weights of the alternatives are calculated by obtaining the eigenvector and eigenvalue using AHP and also the priority vector using FAHP, as presented in Table 6. The consistency ratio for the comparison matrix of the alternatives with respect to the environment is less than $10 \%$, namely $8.51 \%$. This result is considered to be consistent with the judgement towards the 15 alternatives with respect to the environment in terms of conventional AHP and FAHP.

Table 6. Priority vector $(\boldsymbol{w})$ of alternatives with respect to the environment.

\begin{tabular}{clcccc}
\hline \multirow{2}{*}{ No } & \multirow{2}{*}{ Alternatives } & \multicolumn{4}{c}{ Priority vector $(\boldsymbol{w})$} \\
\cline { 3 - 6 } & & FAHP & Rank & AHP & Rank \\
\hline 1 & Cheap & 0.0109 & 15 & 0.0112 & 15 \\
2 & Easy to reuse & 0.1416 & 2 & 0.1589 & 2 \\
3 & Easy to recycle & 0.1252 & 3 & 0.1246 & 3 \\
4 & Less transportation & 0.1163 & 4 & 0.1090 & 4 \\
5 & Easy to manufacture & 0.0201 & 12 & 0.0173 & 12 \\
6 & Durable & 0.0807 & 6 & 0.0663 & 6 \\
7 & Lightweight & 0.0160 & 13 & 0.0136 & 13 \\
8 & Easy to maintain & 0.0130 & 14 & 0.0119 & 14 \\
9 & Reliable & 0.0445 & 8 & 0.0394 & 8 \\
10 & Long lifespan & 0.0344 & 10 & 0.0291 & 10 \\
11 & Impact-resistant & 0.0266 & 11 & 0.0236 & 11 \\
12 & Not easy to break & 0.0401 & 9 & 0.0327 & 9 \\
13 & Free from hazardous substances & 0.1602 & 1 & 0.2119 & 1 \\
14 & Less materials & 0.0554 & 7 & 0.0453 & 7 \\
15 & Environmentally safe & 0.1151 & 5 & 0.1053 & 5 \\
\hline
\end{tabular}

As shown in Table 6, the results computed from the AHP and FAHP with extent analysis methods provide similar priority ranking for the analysed customer requirements while also showing minimal differences in terms of the priority vector scores between both methods. For instance, according to the FAHP method, the top three customer requirements based on the analysis were freedom from hazardous substances, followed by ease of use and easy recycling, and the AHP method produced the same top three customer requirements. This implies that the proposed framework using the FAHP method to calculate the global weight is applicable, since similar preference rankings are obtained from AHP and FAHP for the priority vector.

Validation of the consistency of human judgement, which has become a problem in product design, may be solved by the incorporation of AHP into FAHP with extent analysis. Moreover, according to the results shown, AHP is also applicable for determining human preferences, and specifically for prioritizing customer requirements for product design. Even though the quality of the judgement from a fuzzy environment has been claimed to be more precise and better at dealing with imprecise and vague information, it is proved that the result of the prioritizing is not very different from the judgement in the conventional environment. Customer requirements can be subjective and easily influenced by surroundings. Therefore, more precise and consistent analysis is needed. The proposed framework suggests that the method using FAHP with extent analysis offers benefits from the background of the method in dealing with imprecise and 
vague information in decision making. On the other hand, AHP offers consistent evaluation, which can help the decision maker to check for the consistency of the judgement.

\section{CONCLUSIONS}

A framework of prioritizing customer requirements by incorporating AHP in the FAHP extent analysis work flow is proposed in order to deal with the consistency judgement analysis in the FAHP method. Although more tools are available for decision making, conventional AHP has been applied widely because of the simplicity of the algorithm, and FAHP with extent analysis has been applied in various areas because of its ability to deal with imprecise and vague information during decision making. In contrast, FAHP with extent analysis does not show the validity of the consistency in the judgement and so incorporation of AHP results in a more consistent judgement to tackle subjectivity problems. This study has shown the validity of integrating FAHP with AHP by presenting their similar rankings and the consistency of fuzzy judgement analysed from the AHP method. The consistency ratio obtained from this study is acceptable, at a value below $10 \%$. Thus, FAHP with extent analysis combined with AHP is a suitable tool for prioritizing customer requirements in a consistent judgement and helps the design engineer to identify the most and least important product design requirements.

\section{ACKNOWLEDGEMENTS}

The authors would like to thank Universiti Putra Malaysia for the financial support provided through the Putra Grant IPB (GP-IPB/2014/9441500) as well as to Universiti Teknikal Malaysia Melaka for providing the scholarship award to the principal author in this project.

\section{REFERENCES}

[1] Gangurde SR, Akarte MM. Customer preference oriented product design using AHP-modified TOPSIS approach. Benchmarking: An International Journal. 2013;20(4):549-564.

[2] Nahm YE, Ishikawa $H$, Inoue $M$. New rating methods to prioritize customer requirements in QFD with incomplete customer preferences. International Journal of Advanced Manufacturing Technology. 2013; 65(0):1587-1604.

[3] Dalalah D, Al-oqla F, Hayajneh M. Application of the analytic hierarchy process (AHP) in multi- criteria analysis of the selection of cranes. Jordan Journal of Mechanical and Industrial Engineering. 2010;4(5):567-578.

[4] Saaty TL, Vargas LG. Uncertainty and rank order in the analytic hierarchy process. European Journal of Operational Research. 1987;32(1):107-117.

[5] Saaty TL, Hu G. Ranking by eigenvector versus other methods in the analytic hierarchy process. Applied Mathematics Letters. 1998;11(4):121-125.

[6] Saaty TL. Decision-making with the AHP: Why is the principal eigenvector necessary. European Journal of Operational Research. 2003;145(1):85-91.

[7] Kwong CK, Bai H. A fuzzy AHP approach to the determination of importance weights of customer requirements in quality function deployment. Journal of Intelligent Manufacturing. 2002; 13(5):367-377. 
[8] Chang DY. Applications of the extent analysis method on fuzzy AHP. European Journal of Operational Research. 1996;95(3): 649-655.

[9] Vaidya OS, Kumar S. Analytic hierarchy process: An overview of applications. European Journal of Operational Research. 2006;169(0):1-29.

[10] Hambali A, Sapuan S M, Ismail N, Nukman Y. Application of analytical hierarchy process (AHP) and sensitivity analysis for selecting the best design concepts during conceptual design stage. Multidiscipline Modeling in Materials and Structures. 2009; 5(3):289-294.

[11] Hambali A, Sapuan S M, Rahim AS, Ismail N, Nukman Y. Concurrent decisions on design concept and material using analytical hierarchy process at the conceptual design stage. Concurrent Engineering. 2011;19(2):111-121.

[12] Sapuan SM, Kho JY, Zainudin ES, Leman Z, Ahmed Ali B A, Hambali A. Materials selection for natural fiber reinforced polymer composites using analytical hierarchy process. Indian Journal of Engineering \& Materials Sciences. 2011;18(0):255-267.

[13] Jahan A, Mustapha F, Sapuan SM, Ismail MY, Bahraminasab M. A framework for weighting of criteria in ranking stage of material selection process. International Journal of Advanced Manufacturing Technology. 2012.;58(0):411-420.

[14] Mansor MR, Sapuan SM, Zainudin ES, Nuraini AA, Hambali A. Hybrid natural and glass fibe.rs reinforced polymer composites material selection using Analytical Hierarchy Process for automotive brake lever design. Materials \& Design. 2013; 51(0):484-492.

[15] Mansor MR, Sapuan SM, Zainudin ES, Nuraini AA, Hambali A. Conceptual design of kenaf fiber polymer composite automotive parking brake lever using integrated TRIZ-Morphological Chart-Analytic Hierarchy Process method Materials \& Design. 2014;54(0):473-482.

[16] Ho W. Integrated analytic hierarchy process and its applications - A literature review.European Journal of Operational Research. 2008;186(0):211-228.

[17] Mansor MR, Sapuan SM, Zainudin ES, Nuraini AA, Hambali A. Application of integrated AHP-TOPSIS method in hybrid natural fiber composites materials selection for automotive parking brake lever component. Australian Journal of Basic and Applied Sciences. 2014; 8(5):431-439.

[18] Hanumaiah N, Ravi B, Mukherjee NP. Rapid hard tooling process selection using QFD-AHP methodology. Journal of Manufacturing Technology Management. 2006;17(3):332-350.

[19] Myint S. A framework of an intelligent quality function deployment (IQFD) for discrete assembly environment. Computers \& Industrial Engineering 2003;45(2):269-283.

[20] Kwong CK, Bai H. Determining the importance weights for the customer requirements in QFD using a fuzzy AHP with an extent analysis approach. IIE Transactions. 2003;35(7): 619-626.

[21] Saaty TL. There is no mathematical validity for using fuzzy number crunching in the analytic hierarchy process. Journal of Systems Science and Systems Engineering. 2006;15(4):457-464.

[22] Saaty TL,Tran LT. On the invalidity of fuzzifying numerical judgments in the Analytic Hierarchy Process. Mathematical and Computer Modelling. 2007;46(78): 962-975.

[23] Saaty TL,Tran LT. Fuzzy judgments and fuzzy sets. International Journal of Strategic Decision Sciences. 2010;1(1):23-40. 
[24] Chan HK, Wang X, White GRT, Yip N. An extended fuzzy-AHP approach for the evaluation of green product designs. IEEE Transactions on Engineering Management. 201; 60(2):327-339.

[25] Wang X, Chan HK, Li D. A case study of an integrated fuzzy methodology for green product development. European Journal of Operational Research. 2015; 241(1):212-223.

[26] Kabir G, Akhtar Hasin MH. Comparative analysis of AHP and fuzzy AHP models for multicriteria inventory classification. International Journal of Fuzzy Logic Systems. 2011;1(1):1-16.

[27] Roy MK, Ray A, Pradhan BB. Non-traditional machining process selection using integrated fuzzy AHP and QFD techniques : a customer perspective. Production \& Manufacturing Research: An Open Access Journal 2014;2,(1):530-549.

[28] Sakthivel G, Ilangkumaran M, Nagarajan G, Shanmugam P. Selection of best biodiesel blend for IC engines: an integrated approach with FAHP-TOPSIS and FAHP-VIKOR. International Journal of Oil, Gas and Coal Technology 2013;6, (5):581-596.

[29] Kabir G, Hasin MAA. Multi-criteria inventory classification through integration of fuzzy analytic hierarchy process and artificial neural network. International Journal and Systems Engineering. 2013;14(1):74-103.

[30] Chen Z, Yang W. An MAGDM based on constrained FAHP and FTOPSIS and its application to supplier selection. Mathematical and Computer Modelling. 2011;54(11-12): 2802-2815.

[31] Chen CJ, Yang SM,. Chang SC. A model integrating fuzzy AHP with QFD for assessing technical factors in aviation safety. International Journal of Machine Learning and Cybernetics. 2013;5(5):761-774.

[32] Faiz MT, Badrul O. Application of house of quality, fuzzy-analytical hierarchy process and rough-grey analysis in design concept evaluation-a case study. Journal of Mechanical Engineering and Sciences. 2013;5(0):723-733.

[33] Ishizaka A. Comparison of fuzzy logic, AHP, FAHP and hybrid fuzzy AHP for new supplier selection and its performance analysis. International Journal of Integrated Supply Management. 2014;9(1991):1-22.

[34] Wang YM, Elhag TMS. On the normalization of interval and fuzzy weights. Fuzzy Sets and Systems. 2006;157(18)2456-2471.

[35] Wang YM, Luo Y, Hua Z. On the extent analysis method for fuzzy AHP and its applications. European Journal of Operational Research. 2008;186(2):735-747.

[36] Zhü K. Fuzzy analytic hierarchy process: Fallacy of the popular methods. European Journal of Operational Research. 2014;236(1):209-217.

[37] Liou TS, Wang MJJ. Ranking fuzzy numbers with integral value. Fuzzy Sets and Systems. 1992;50(3):247-255.

[38] $\mathrm{Xu} \mathrm{Z}$, Wei C. Consistency improving method in the analytic hierarchy process. European Journal of Operational Research. 1999;116(2): 443-449.

[39] Raharjo H, Endah D. Evaluating relationship of consistency ratio and number of alternatives on rank reversal in the AHP. Quality Engineering. 2006;18(0): 39-46.

[40] Bharane P, Tanpure K, Patil A, Kerkal G. Design , analysis and optimization of anti-roll bar. International Journal of Engineering Research and Applications. 2014;4( 9):137-140.

[41] Shinde P, Patnaik MMM.Parametric optimization to reduce stress concentration at corner bends of solid and hollow stabilizer bar. International Journal of Research on Aeronautical and Mechanical Engineering. 2013;1(4):1-15. 
[42] Bharane P, Tanpure K, Kerkal G. Optimization of anti-roll bar using Ansys Parametric Design Language ( APDL). nternational Journal of Engineering Research and General Science. 2014;2(5):699-706.

[43] Prawoto Y, Djuansjah JRP, Tawi KB, Fanone MM. Tailoring microstructures: A technical note on an eco-friendly approach to weight reduction through heat treatment. Materials \& Design. 2013;50(0): 635-645.

[44] Bora PM. Vehicle anti-roll bar analyzed using FEA. International Journal of Advanced Technology in Engineering and Science. 2014;2(7):130-136.

[45] Sharma K, Bora PM, Sharma PK. Hollow cross-section vs . solid cross-section \& increasing the diameter of solid cross-section by using finite element analysis of anti-roll bar. International Journal of Advanced Research in Science and Engineering. 2012;1(1):1-11.

[46] Wittek AM, Richter HC, Lazarz B. Stabilizer bars: Part 1 . Calculations and construction. Transport Problems. 2010; 5(4):135-143.

[47] Wittek AM, Richter HC, Lazarz B. Stabilizer bars : Part 2 . Calculations-example. Transport Problems. 2011; 6(1):137-145. 